\title{
Applying Educational Theory to Optimize Trainee Education in the Ambulatory Virtual Care Environment
}

\author{
Lisa Zickuhr ${ }^{1}$ iD . Jason Kolfenbach ${ }^{2}$ D . Marcy B. Bolster ${ }^{3}$ D
}

Accepted: 30 July 2021 / Published online: 17 August 2021

(C) International Association of Medical Science Educators 2021

\begin{abstract}
Virtual care (VC) encounters have become an essential part of outpatient clinical care. The theory of situated learning and legitimate peripheral participation posits that medical trainees learn best when they participate in authentic patient care experiences and engage effectively with their preceptors, members of the health care team, and the clinical learning environment. This theory can provide a framework from which to approach teaching in the VC setting, whereby preceptors may capitalize on the unique learning and assessment opportunities provided during VC encounters and optimize educational experiences for trainees as well as clinical outcomes for patients. In this monograph, we propose an approach grounded in situated learning and legitimate peripheral participation for teaching in the VC environment, particularly during real-time video visits.
\end{abstract}

Keywords Situated learning theory $\cdot$ Virtual care $\cdot$ Telehealth $\cdot$ Teaching in the ambulatory setting

\section{Introduction}

Virtual care (VC), defined as the use of technology to deliver care remotely to patients, has become an essential component of the clinical environment. The COVID-19 pandemic transformed its utilization from a small facet of care delivery into mainstream practice [1]. Not only does VC help clinicians maintain safe patient care and learning environments during social distancing, but it also prompts educators to develop learners' skills and competencies for virtual practice and to capitalize on unique curricular and assessment opportunities [2]. In doing so, $\mathrm{VC}$ can enhance both clinical care and training, particularly when treating patients whose circumstances limit their access to inperson care.

Virtual care is conducted synchronously or asynchronously through several modalities, including videoconferencing, audio-only interactions, electronic messaging,

Lisa Zickuhr

zickuhrl@wustl.edu

1 Department of Medicine, Washington University School of Medicine, St. Louis, MO, USA

2 Department of Medicine, University of Colorado School of Medicine, Aurora, CO, USA

3 Department of Medicine, Massachusetts General Hospital, Boston, MA, USA and mobile health applications [3]. Studies comparing patient satisfaction and health outcomes among these mechanisms are ongoing [4], and it may emerge that these modalities serve distinct but complementary roles in virtual patient care. Representing a large proportion of VC since the onset of the COVID-19 pandemic, real-time video (RTV) encounters enable providers to obtain clinical information, conduct an exam, and develop management plans. In this monograph, we will focus on the use of RTV for synchronous VC delivery in the training environment. We will use the term "virtual care" to broadly reflect any method that uses technology to deliver patient care remotely and "real-time video" to specify patient encounters that occur through videoconferencing.

Opportunities for training in the virtual ambulatory environment span the spectrum from shadowing to precepting trainees in faculty clinics to supervising residents and fellows in their own continuity clinics [5]. Faculty utilize many techniques for precepting trainees in the inperson environment that optimize learning and training. Some of these techniques can be applied directly to teaching during RTV encounters, while others require rethinking and restructuring to meet the needs of learners and their level of training as well as to adapt to the distinctive features of the virtual environment. We propose an approach grounded in situated learning and legitimate 
peripheral participation for teaching in the RTV environment as well as for leveraging unique learning opportunities during these encounters [6].

\section{The Theory of Situated Learning and Legitimate Peripheral Participation}

In their theory of situated learning and legitimate peripheral participation, Lave and Wenger describe education as a social process that occurs when students take part in authentic work experiences [6]. These "legitimate" experiences are embedded, or "situated," within the learning environment. The learning environment encompasses the “...social interactions, organizational cultures and structures, and physical and virtual spaces that surround and shape participants' experiences, perceptions, and learning [7]." Situated learning positions learners at the center of education to most actively engage in legitimate participation as well as interact with the surrounding environment and the individuals who contribute to these learning experiences. This form of education is distinct from didactic teaching in which instructors assume the central role and transmit knowledge to learner recipients. Learning can be measured when students advance from novice "newcomers" positioned at the "periphery" of a continuum of acculturation and competence to expert "old-timers" who are able to fully participate in high-ordered skills. Educators facilitate this process when they provide learning experiences appropriate for students' levels of understanding and skill while optimizing their interaction with the learning environment.

When situated learning and legitimate peripheral participation are applied to medical education in the ambulatory setting, trainees take part in encounters that contribute to patient care (Fig. 1). They also engage with the clinical learning environment, for instance interacting with the workflows and layout of the ambulatory space, the electronic health record, as well as interprofessional team members and supervising faculty. Preceptors assign trainees to participate in patient encounters that will promote the expansion of their knowledge and skills without challenging them with situations that are beyond the reach of their level of training. Teaching faculty observe trainees to assess their performance, provide feedback, and engage them in reflective dialog to advance their clinical competence. As RTV visits integrate into the ambulatory clinical learning environment, faculty preceptors can apply situated learning and legitimate peripheral participation to enrich the educational experience rather than merely using virtual encounters as a replacement for in-person care and training.

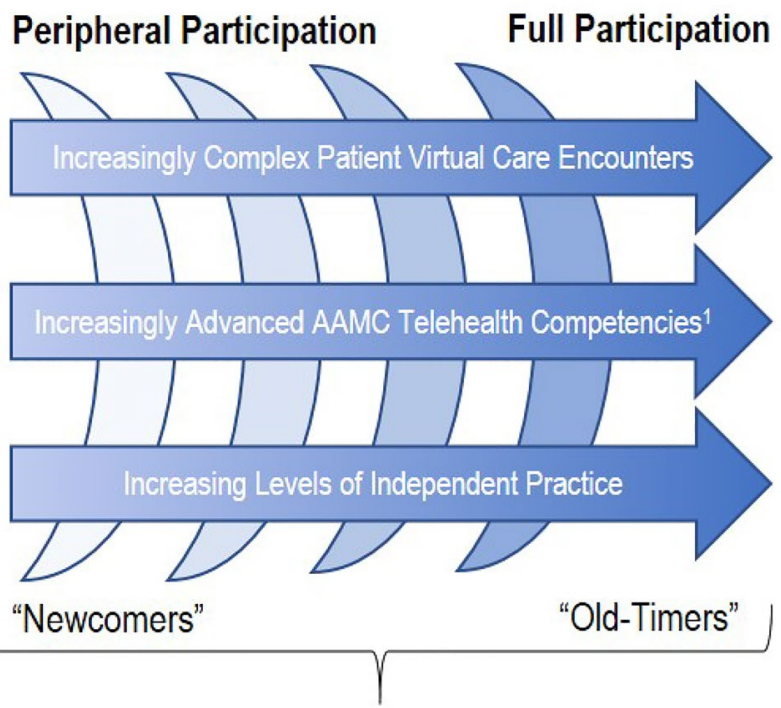

Preceptors engage trainees in the physical and virtual learning environments, authentic virtual care patient encounters, dialog, feedback, and selfreflection.

Fig. 1 An approach to teaching during virtual care (VC) encounters in the framework of situated learning and legitimate peripheral participation. Preceptors should engage learners' participation in virtual patient encounters that match their level of training. Medically straightforward VC encounters that incorporate the foundational levels of the AAMC Telehealth Competencies are best suited for novice "newcomers," while experienced "old-timers" should be paired with VC encounters that are more medically complex and use more advanced telehealth competencies. Preceptors facilitate learning and the transformation from peripheral to full participation when they discuss teaching points, provide feedback on learners' performance during VC encounters, and direct trainees' self-reflections

\section{Establishing the Clinical Learning Environment}

A well-constructed clinical learning environment optimizes the context in which legitimate peripheral participation can occur and best permits trainees to learn. The learning environment begins with the layout of the physical teaching space. Assigning an exam room or workstation to trainees in ambulatory clinics integrates them into the workflow and improves the educational quality of their experiences $[8,9]$. During RTV encounters, learners similarly should have dedicated workspace and teleconferencing equipment for conducting clinical visits, enhancing the degree to which they can practice and develop their VC knowledge and skills.

Videoconferencing platforms set the backdrop of the virtual learning environment, introducing features unique to training and to virtual patient care [10]. The 
programming of the virtual platform is one such feature, and faculty should orient learners to its functionality so trainees can most fully participate in RTV tasks such as admitting patients from the virtual waiting room, reviewing clinical data with patients through screen share options, and appropriately documenting the virtual encounter in the electronic health record. Also unique to the VC learning environment is the coordination of care delivery and teaching between trainees and preceptors, who may be participating remotely from different locations [10]. In these instances, telephone calls can facilitate verbal communication between trainees and preceptors, and some videoconferencing platforms include a "waiting room" which can be used for teaching, providing feedback, and addressing trainees' and preceptors' learning objectives at the virtual point of care without the patient being present.

Medical educators recognize the importance of a preclinic huddle to acclimate trainees to the learning environment $[5,11]$. A pre-clinic huddle for RTV visits should delineate the physical and virtual spaces, explain workflows as they occur in these environments, and exchange learners' goals and preceptors' expectations [12]. Faculty should share instructions for using the RTV platform, troubleshooting technology glitches, and documenting in the electronic health record. The pre-clinic huddle can be implemented through email, phone, or in-person prior to the clinic session and may vary based on the physical proximity of the preceptor to the trainee as well as the learner's degree of familiarity with the virtual environment. These steps lay the groundwork for organized RTV experiences that optimize addressing learners' goals and preceptors' expectations while delineating the context in which trainees will participate in patient care and enhance their VC skills.

\section{Providing Authentic Learning Experiences}

Learners best develop knowledge and hone their skills when they participate in authentic patient care experiences tailored to their level of competence. "Newcomer" trainees admit that limited experience in virtual medicine may restrict their participation during VC encounters [13], and they may benefit from an introduction to fundamental VC skills [14]. Preceptors can role model to help trainees acclimate to the new clinical environment, demonstrating workflows for RTV visits as well as skills in "webside" manner, expressing empathy, and the virtual physical exam $[15,16]$. Role modeling can help orient novice trainees to the nuances of history-taking and physical examination in the RTV environment in order to equip them with the skills they need to participate in virtual patient encounters with progressive levels of independence.
The Association of American Medical Colleges (AAMC) published Telehealth Competencies to address achievement of proficiency in the unique skills required for VC [17]. The competencies include six domains as listed in Table 1. The acquisition of skills increases in complexity across the spectrum of providers from recent medical school graduates to experienced faculty physicians, reflecting the progression from peripheral to full participation in VC. This structure provides a framework for faculty preceptors to focus on the basic competencies with earlier learners while challenging experienced trainees to attain more advanced levels of competency. As an example, Lockwood and colleagues describe scenarios in which medical students might be expected to obtain histories and perform physical exams during virtual rheumatology encounters, while rheumatology fellows may be expected to gather data and synthesize it into an evaluation and management plan [18].

The six domains of the AAMC Telehealth Competencies provide metrics for learners to strengthen their VC knowledge and skill sets [17]. These domains are comprehensive and broad, and it is neither practical nor feasible to address all of them in a single patient care encounter. Preceptors should organize trainees' experiences to maximize learning [6], intentionally referencing one or two AAMC Telehealth Competencies during a virtual visit and layering lessons in subsequent encounters.

Patient selection and scheduling are critical elements when tailoring RTV learning opportunities to trainees' skill levels. The timing of trainees' patient encounters should maximize learning, as it may be unwise to assign them consecutive virtual visits if time is needed to adapt to RTV. Preceptors also can select patients with more straightforward medical problems to direct the focus of trainees who are less experienced in RTV, thereby avoiding superimposed medical complexity [19].

A strong partnership between patients and medical providers facilitates teaching in the virtual space. As during in-person visits [20], this collaboration in the RTV environment can empower patients to assume the role of primary teacher, emphasizing key aspects of their histories, providing feedback to learners on virtual exam techniques, and often knowing which camera angles and lighting best demonstrate their own exam findings.

\section{Capitalizing on Unique Learning Opportunities During Real-Time Video Visits}

Medical training programs track learners' progression from peripheral to fully participating health care providers along competency-based clinical metrics. Undergraduate and graduate medical educators identify several skills within the domains of medical knowledge, patient care, communication 
Table 1 Examples of teaching points for each domain of the AAMC Telehealth Competencies ${ }^{\mathrm{a}}$

\begin{tabular}{|c|c|}
\hline Domain & Example teaching points \\
\hline Patient safety and appropriate use of telehealth & $\begin{array}{l}\text { - Teaching components of informed consent for virtual encounters } \\
\text { - Discussing patient characteristics that optimize selection for virtual care (VC) visits } \\
\text { - Instructing selection of diseases and conditions which are most amenable to VC } \\
\text { encounters versus in-person visits } \\
\text { - Identifying ways VC facilitates interprofessional collaborative care delivery }\end{array}$ \\
\hline Data collection and assessment via telehealth & $\begin{array}{l}\text { - Comparing exam accuracy when performed in-person versus virtually }{ }^{\mathrm{b}-\mathrm{d}} \\
\text { - Providing feedback on virtual exam skills } \\
\text { - Incorporating patient-reported data (i.e., blood pressure, pulse oximetry, blood glucose } \\
\text { measurements, patient-reported outcomes) into the clinical assessment }{ }^{\mathrm{e}}\end{array}$ \\
\hline Communication via telehealth & $\begin{array}{l}\text { - Developing "webside" manner skills } \\
\text { - Critiquing non-verbal communication } \\
\text { - Suggesting methods to demonstrate empathy during VC visits }\end{array}$ \\
\hline Ethical practices and legal requirements for telehealth & $\begin{array}{l}\text { - Identifying possible threats to patient privacy during VC encounters } \\
\text { - Discussing medical malpractice laws pertaining to VC }\end{array}$ \\
\hline Technology for telehealth & $\begin{array}{l}\text { - Defining both the applications and limitations of technology in VC } \\
\text { - Practicing troubleshooting patients' technology barriers } \\
\text { - Demonstrating practices that optimize efficient VC delivery (i.e. using dual screens for } \\
\text { electronic health record data review and documentation) }\end{array}$ \\
\hline Access and equity in telehealth & $\begin{array}{l}\text { - Identifying patients with limited access to the technology needed for virtual encounters } \\
\text { - Applying virtual care appropriately to overcome health inequity } \\
\text { - Discussing the readiness and willingness of various patient populations to use VC }\end{array}$ \\
\hline
\end{tabular}

${ }^{a}$ Kitts AB, Chandra S, Evans N, et al. Telehealth competencies across the learning continuum. In: New and Emerging Areas in Medicine Series. Association of American Medical Colleges. 2021. https://store.aamc.org/downloadable/download/sample/sample_id/412/. Accessed 27 Mar 2021

${ }^{b}$ Lee AC, Davenport TE, Randall K. Telehealth physical therapy in musculoskeletal practice. The Journal of orthopaedic and sports physical therapy. 2018;48(10):736-739

${ }^{c}$ Lowitt MH, Kessler II, Kauffman CL, Hooper FJ, Siegel E, Burnett JW. Teledermatology and in-person examinations: a comparison of patient and physician perceptions and diagnostic agreement. Archives of dermatology. 1998;134(4):471-476

${ }^{\mathrm{d}}$ Wood J, Wallin M, Finkelstein J. Can a low-cost webcam be used for a remote neurological exam? Studies in health technology and informatics. 2013;190:30-32

eEngland BR, Barber CEH, Bergman M, Ranganath VK, Suter LG, Michaud K. Brief report: Adaptation of American College of Rheumatology rheumatoid arthritis disease activity and functional status measures for telehealth visits. Arthritis care \& research. 2020;(acr.24429). 10.1002/acr. 24429

skills, professionalism, and practice-based learning improvement as essential to the development of practicing physicians $[21,22]$. Some skills are easier to teach or assess [22], and RTV encounters offer opportunities to address those that can be challenging to identify during in-person care, such as completing informed consent, assessing patient safety, and providing equitable health care.

\section{Informed Consent}

Informed consent contributes to shared decision-making between patients and health care providers, yet retrospective studies demonstrate that physicians rarely execute the process completely [23]. It is standard of care for patients to grant their informed consent regarding the risks, benefits, and alternatives to RTV visits at the beginning of each encounter [17], and sequential RTV visits provide learners with opportunities to practice the process reiteratively. Even when office staff obtain patients' consent for RTV encounters, trainees should be aware of its importance and verify that it was completed correctly before proceeding with the virtual visit.

\section{Patient Environment and Safety}

Formal instruction on patient safety often is lacking in medical education [24], but the RTV setting fosters the development of skills requisite for surveying patients' environments [17]. Preceptors should direct trainees to scan the setting shared through RTV and address possible threats to patient safety at the beginning of virtual encounters. This can take such forms as noticing that a patient may be driving and requesting that the patient park the car to minimize distractions. Similarly, the provider may suggest that a patient in a public location move to a private space before proceeding with the RTV appointment. In addition, learners can practice asking patients about their environments in a sensitive and culturally-aware manner 
to verify safety and privacy beyond what is visualized in the videoconferencing screen. Such patient care experiences help learners hone the skills needed to screen for safety in patients' environments.

Plans directing when and how patients will follow-up with their providers further contribute to patient safety. The ability to optimally identify patients as candidates for virtual visits is requisite to the practice of $\mathrm{VC}$ and starts at the visit prior, which may be in-person, when providers and patients decide on care plans [17, 25]. Teaching this skill is especially relevant when precepting in residents' and fellows' continuity clinics to optimize the safety of trainees' patient panels, reflecting on how patients' diagnoses, disease severity, and amenability to RTV visits should influence decision-making.

\section{Social Determinants of Health and Health Equity}

The World Health Organization Commission on Social Determinants of Health (SDH) called for an increase in SDH education in all levels of medical training, which has proved difficult to integrate across curricula [26-28]. VC offers a novel platform and unique opportunity to engage trainees in recognizing factors that affect health equity and developing structural competency to work towards alleviating them [29]. RTV visits allow trainees to assess patients' living environments, whereby each encounter essentially can become a home visit with assessment of situational factors contributing to health outcomes [30]. VC can extend the reach of health services, raising the need that we equip trainees with VC skills to treat underserved populations lacking access to care $[31,32]$. In doing so, VC opens a new door to health equity education previously unexplored in medical training that can improve outcomes for underserved patients.

Providers similarly should recognize occasions in which VC could exacerbate health inequity. For example, a significant number of patients lack access to broadband internet, a resource needed for VC [33]. The COVID-19 pandemic highlighted this "digital divide," and disenfranchised patients experienced greater disruptions to their health care [34]. Faculty preceptors should instruct trainees to identify potential threats to health equity as well as carefully consider alternative methods of care delivery. For instance, when offering audio-only encounters to patients who lack broadband internet access, providers should balance the method's ease of availability with the quality of clinical information that can be obtained compared to in-person or RTV visits. Learners and preceptors also may discuss patient advocacy initiatives focused on providing broadband access to disenfranchised patients as opportunities for community outreach.

\section{Observing and Assessing a Learner's Performance}

Observation and assessment of trainees fulfills the dual purpose of providing specific suggestions for trainees to improve their skills and of sharing evaluative data with oversight committees [35]. Observation of trainees' skills during RTV encounters can follow various paths depending on learning goals and clinic type. In their recommendations for incorporating medical students into the RTV learning environment, Iancu and colleagues describe one method for integrating learners into RTV consultations that follows the traditional staffing model in ambulatory care (Fig. 2A) [14], and we offer two alternative approaches that facilitate direct observation and bedside teaching (Fig. 2B, C).

Direct observation facilitates competency-based education and assessment. It measures learner performance at the peak of Miller's pyramid ("does") and is most effective when completed during the authentic clinical work advocated in legitimate peripheral participation [36]. Videoconferencing assists direct observation more than might happen during in-person clinical encounters because preceptors can enter and exit virtually with less disruption, observing for the entire or just part of the RTV visit. To improve the quality of direct observation, preceptors should minimize their presence and facilitate authentic interactions between trainees and patients [36], such as by pausing video input and muting the microphone to make themselves effectively "invisible." Direct observation provides an opportunity to watch learners not only gather clinical data but also build alliances with patients, demonstrate empathy, and practice shared decision-making. Published checklists may guide observers' focus when assessing learners' VC skills [12]. These workplace-based assessment strategies can enhance the quality of feedback provided to trainees and optimize evaluation of their general medical and VCspecific knowledge and patient care skills [37].

Bedside teaching incorporates direct observation, streamlines ambulatory clinical teaching, and appeals to patients, learners, and teachers [38-40]. "Webside" teaching similarly can eliminate redundancy in RTV encounters while providing high-quality assessment of trainees' performance. Preceptors can directly observe entire or parts of virtual visits or guide trainees to present their findings at the "webside" before asking clarifying questions and providing feedback on the learner's performance. When trainees present at the "webside," patients can verify that information is relayed accurately, and preceptors are not obliged to repeat questions already addressed by the trainee. Patients appreciate the opportunity to listen to providers as they clinically reason through their cases, which enhances the experience 


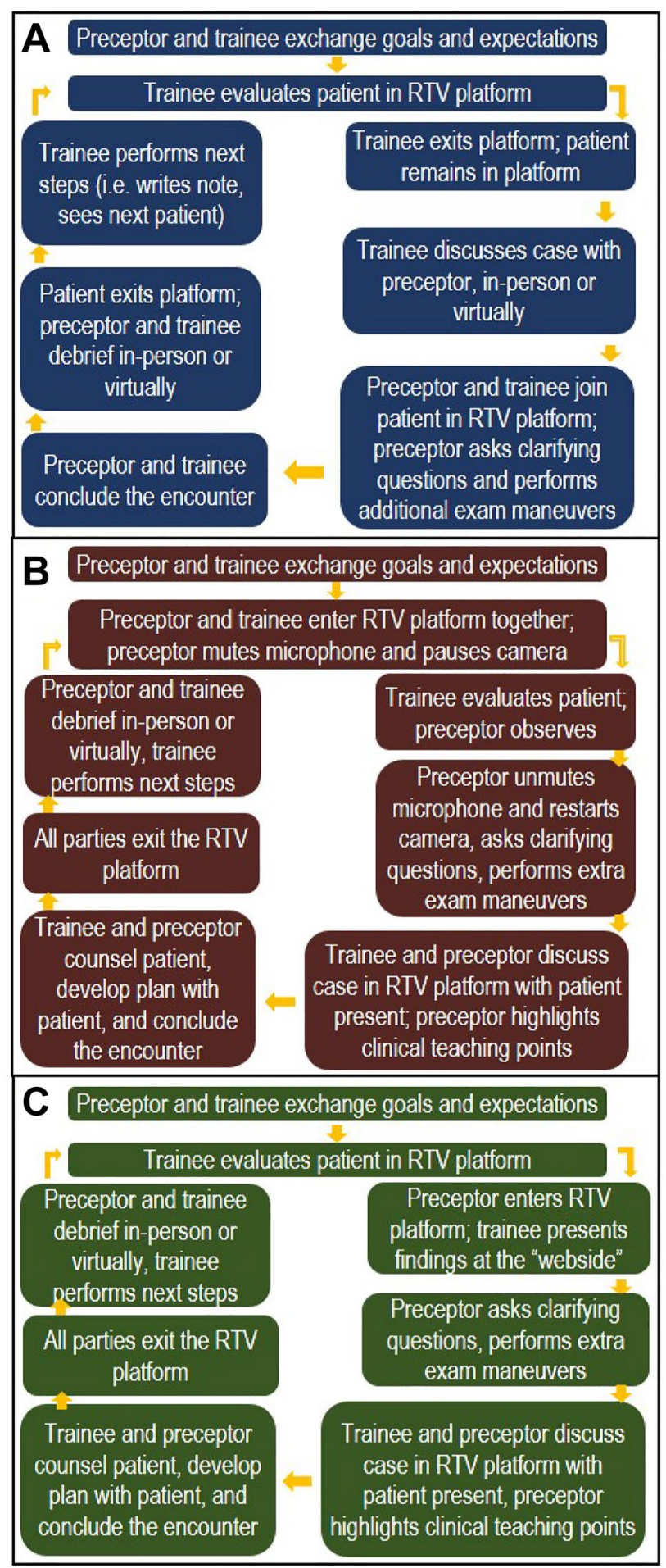

Fig. 2 Proposed workflows for incorporating trainees into real-time video (RTV) encounters, where $\mathbf{A}$ the trainee evaluates the patient independently and presents to the preceptor one-on-one, $\mathbf{B}$ the preceptor directly observes the session, or $\mathbf{C}$ the trainee evaluates the patient independently and presents at the "webside". Panel A is adapted from Iancu AM, Kemp MT, Gribbin $W$ et al. Twelve tips for the integration of medical students into telemedicine visits. Med Teach, 2020 [14] and facilitates patient counseling [38]. "Webside" teaching streamlines the time faculty members devote to patient evaluations, while both enriching the patient care alliance and providing patient-centered care.

\section{Communicating to Advance Learning and Provide Feedback}

In situated learning, communication between trainees and preceptors invites learners to advance their knowledge and skill sets [6]. This contrasts with didactic learning, where speaking is a conduit for knowledge transfer. Preceptor teaching techniques, such as SNAPPS, the One-Minute Preceptor, thinking aloud, and comparing and contrasting different patient encounters can start discussions between faculty preceptors and trainees that stimulate self-reflection and guide learning for trainees [41-45]. Teaching topics may include items particular to general medicine or $\mathrm{VC}$, as outlined in the domains of the AAMC Telehealth Competencies (Table 1) [17].

Feedback represents another medium through which conversation between learners and faculty preceptors opens the door to learning. RTV visits offer flexibility for feedback to occur virtually or in-person. When delivering feedback in videoconferencing platforms, the preceptor relies on verbal communication to convey suggestions for improvement without being in the physical presence of patients on whom to demonstrate skills. Just as non-verbal communication rises in importance during RTV patient encounters, so too does it become more crucial when interacting with trainees virtually [46]. Body language, eye contact, and facial expression help convey the preceptor's interest in the learner's education and improve the reception of feedback.

The workflow of RTV encounters provides options for the timing of feedback, such that it can take place immediately following a patient encounter, upon completion of the clinical session, or at a later time depending on the purpose of the feedback. Preceptors should share suggestions for improving specific behaviors in close approximation to trainees' performance to maximize skill development. On the other hand, feedback on overall performance might best be relayed at a later time, allowing the trainee to become more familiar with clinical context, for preceptors to organize their points of discussion, and for both parties to engage in feedback purposefully.

\section{Recognizing Opportunities to Improve Preceptor Performance}

Learning requires co-participation from trainees and teachers, and both parties can develop an enhanced knowledge base and skill set through the process [6]. VC is still in its infancy despite widespread uptake during the COVID-19 pandemic. The foundation of evidence for VC delivery is 
growing but remains limited, and guidelines for VC implementation and trainee instruction are often based on expert opinion [10,47]. As clinicians continue to develop their virtual medicine skills, learners also contribute to the collective understanding, possibly demonstrating new ways to convey empathy, conduct exam maneuvers in the virtual setting, or develop strategies to assist patients with technology challenges. In addition, feedback regarding the educational experience is a bidirectional dialog that invites preceptors to gain insights from learners that should serve to enhance teaching skills in the VC environment.

\section{Conclusion}

Virtual care, especially in the form of RTV visits, offers an enriched patient care environment across the spectrum of learners and should be used to enhance, rather than merely replace, our ability to provide clinical care. It provides opportunities for learners and preceptors to develop VC skills while revealing options to instruct and assess trainees' approaches to informed consent, communication skills, social determinants of health, and patient safety assessment. Learning experiences should be embedded within the $\mathrm{VC}$ environment and should encourage trainees to interact with teleconferencing platforms as well as patients and health care team members. In the context of situated learning and legitimate peripheral participation, teaching during VC encounters can uphold the quality of learning experiences. In exchange, learners, patients, and teaching faculty will optimize health care delivery while enhancing education and training experiences.

Author Contribution All authors contributed to the conceptualization and writing of this monograph. The first draft of the manuscript was written by Lisa Zickuhr, and all authors commented on previous versions of the manuscript. All authors read and approved the final manuscript.

Funding This work was supported by the Rheumatology Research Foundation's Clinician Scholar Educator Award under Grant CSE2122.

\section{Declarations}

Competing Interests The authors declare no competing interests.

\section{References}

1. Koonin LM, Hoots B, Tsang CA, et al. Trends in the use of telehealth during the emergence of the COVID-19 pandemicUnited States, January-March 2020. MMWR Morb Mortal Wkly Rep. 2020;69:1595-1599. Published 2020 Oct 30. https://doi. org/10.15585/mmwr.mm6943a3.
2. Jumreornvong O, Yang E, Race J, Appel J. Telemedicine and medical education in the age of COVID-19. Acad Med. 2020;95:183843. https://doi.org/10.1097/ACM.0000000000003711.

3. Tuckson RV, Edmunds M, Hodgkins ML. Telehealth. N Engl J Med. 2017;377(16):1585-92. https://doi.org/10.1056/NEJMsr1503323.

4. Clinicaltrials.gov. Comparing modes of telehealth delivery: phone vs. video visits (ASSIST). ClinicalTrials.gov. 2020. Available at: https://clinicaltrials.gov/ct2/show/nct04616118. Accessed $27 \mathrm{Mar}$ 2021.

5. Fields SA, Usatine R, Steiner E. Teaching medical students in the ambulatory setting: strategies for success. JAMA. 2000;283:23624. https://doi.org/10.1001/jama.283.18.2362.

6. Lave J, Wenger E. Situated learning: legitimate peripheral participation. New York: Cambridge University Press; 1991.

7. Irby, DM. Improving environments for learning in the health professions. Recommendations from the Macy Foundation Conference. Josiah M. Jr. Foundation. 2018. https://macyfoundation.org/ assets/reports/publications/macy_monograph_2018_webfile.pdf. Accessed 27 Mar 2021.

8. Dent JA. AMEE Guide No 26: clinical teaching in ambulatory care settings: making the most of learning opportunities with outpatients. Med Teach. 2005;27:302-15. https://doi.org/10.1080/ 01421590500150999.

9. Nordquist J, Chan MK, Maniate J, Cook D, Kelly C, McDougall A. Examining the clinical learning environment through the architectural avenue. Med Teach. 2019;41:403-7. https://doi.org/10. 1080/0142159X.2019.1566603.

10. Billings H, Genkins J, Johnson E, Li B, Smith S. Engaging learners in telemedicine visits: workflows to support teaching, feedback, and billing. Medical education webinars and virtual discussions. 2021. Available at: https://www.ama-assn.org/ education/accelerating-change-medical-education/medicaleducation-webinars-and-virtual-discussions. Accessed 27 Mar 2021.

11. Elnicki DM, Zalenski D. Integrating medical students' goals, self-assessment and preceptor feedback in an ambulatory clerkship. Teach Learn Med. 2013;25:285-91. https://doi.org/10.1080/ 10401334.2013.827971.

12. Hovaguimian A, Joshi A, Onorato S, Schwartz AW, Frankl S. Twelve tips for clinical teaching with telemedicine visits [published online ahead of print, $2021 \mathrm{Feb} 8$ ]. Med Teach. 2021;1-7. https://doi.org/10.1080/0142159X.2021.1880558.

13. Schifeling W. Telehealth 101: an essential course for all medical students. Acad Med. 2020;95:e10-9. https://doi.org/10.1097/ ACM.0000000000003606.

14. Iancu AM, Kemp MT, Gribbin W, et al. Twelve tips for the integration of medical students into telemedicine visits [published online ahead of print, 2020 Nov 15]. Med Teach. 2020;1-7. https://doi.org/10.1080/0142159X.2020.1844877.

15. Benbassat J. Role modeling in medical education: the importance of a reflective imitation. Acad Med. 2014;89:550-4. https://doi. org/10.1097/ACM.0000000000000189.

16. Passi V, Johnson S, Peile E, Wright S, Hafferty F, Johnson N. Doctor role modelling in medical education: BEME Guide No. 27. Med Teach. 2013;35:e1422-36. https://doi.org/10.3109/ 0142159X.2013.806982.

17. Kitts $\mathrm{AB}$, Chandra S, Evans N, et al. Telehealth competencies across the learning continuum. In: New and emerging areas in medicine series. Association of American Medical Colleges. 2021. https://store.aamc.org/downloadable/download/sample/ sample_id/412/. Accessed 27 Mar 2021.

18. Lockwood MM, Wallwork RS, Lima K, Dua AB, Seo P, Bolster MB. Telemedicine in adult rheumatology: in practice and in training [published online ahead of print, 2021 Feb 8]. Arthritis Care Res (Hoboken). 2021. https://doi.org/10.1002/acr.24569. 
19. Simon SR, Davis D, Peters AS, Skeff KM, Fletcher RH. How do precepting physicians select patients for teaching medical students in the ambulatory primary care setting? J Gen Intern Med. 2003;18:730-5. https://doi.org/10.1046/j.1525-1497.2003.20838.x.

20. Jha V, Quinton ND, Bekker HL, Roberts TE. What educators and students really think about using patients as teachers in medical education: a qualitative study. Med Educ. 2009;43:449_ 56. https://doi.org/10.1111/j.1365-2923.2009.03355.x.

21. Englander R, Cameron T, Ballard AJ, Dodge J, Bull J, Aschenbrener CA. Toward a common taxonomy of competency domains for the health professions and competencies for physicians. Acad Med. 2013;88:1088-94. https://doi.org/10.1097/ACM.0b013e31829a3b2b.

22. Eno C, Correa R, Stewart NH, et al. Milestones guidebook for residents and fellows. ACGME. 2020. https://www.acgme.org/Portals/ 0/PDFs/Milestones/MilestonesGuidebookforResidentsFellows.pdf. Accessed 27 Mar 2021.

23. Cordasco KM. Making health care safer II: an updated critical analysis of the evidence for patient safety practices. Agency for Healthcare Research and Quality, US Department of Health and Human Services. 2013. https://www.ahrq.gov/ sites/default/files/wysiwyg/research/findings/evidence-basedreports/services/quality/patientsftyupdate/ptsafetyII-full.pdf. Accessed 27 Mar 2021.

24. Jain CC, Aiyer MK, Murphy E, et al. A national assessment on patient safety curricula in undergraduate medical education: results from the 2012 clerkship directors in internal medicine survey. J Patient Saf. 2020;16(1):14-8. https://doi.org/10.1097/ PTS.0000000000000229.

25. Kulcsar Z, Albert D, Ercolano E, Mecchella JN. Telerheumatology: a technology appropriate for virtually all. Semin Arthritis Rheum. 2016;46(3):380-5. https://doi.org/10.1016/j.semarthrit.2016.05.013.

26. Marmot M. Closing the health gap in a generation: the work of the Commission on Social Determinants of Health and its recommendations. Glob Health Promot. 2009; Suppl 1:23-27. https://doi.org/10.1177/1757975909103742.

27. Marshall JK, Cooper LA, Green AR, et al. Residents' attitude, knowledge, and perceived preparedness toward caring for patients from diverse sociocultural backgrounds. Health Equity. 2017;1:4349. Published 2017 Feb 1. https://doi.org/10.1089/heq.2016.0010.

28. AAMC. Social determinants for health by academic level. 2021. Available at: https://www.aamc.org/data-reports/curriculumreports/interactive-data/social-determinants-health-academiclevel. Accessed 27 Mar 2021.

29. Siegel J, Coleman DL, James T. Integrating social determinants of health into graduate medical education: a call for action. Acad Med. 2018;93:159-62. https://doi.org/10.1097/ACM.0000000000002054.

30. Moo LR. Home Video Visits: Two-dimensional view of the Geriatric 5 M's. J Am Geriatr Soc. 2020;68:2425-7. https://doi. org/10.1111/jgs.16843.

31. Camhi SS, Herweck A, Perone H. Telehealth training is essential to care for underserved populations: a medical student perspective [published online ahead of print, 2020 Jun 15]. Med Sci Educ. 2020;1-4. https://doi.org/10.1007/s40670-020-01008-w.

32. Kavadichanda C, Shah S, Daber A, et al. Tele-rheumatology for overcoming socioeconomic barriers to healthcare in resource constrained settings: lessons from COVID-19 pandemic [published online ahead of print, 2020 Dec 7]. Rheumatology (Oxford). 2020;keaa791. https://doi.org/10.1093/rheumatology/keaa791

33. Health.gov. Social Determinants of Health - Healthy People 2030 I health.gov. 2021. Available at: https://health.gov/healthypeople/ objectives-and-data/social-determinants-health. Accessed 27 Mar 2021.

34. Ramsetty A, Adams C. Impact of the digital divide in the age of COVID-19. J Am Med Inform Assoc. 2020;27:1147-8. https:// doi.org/10.1093/jamia/ocaa078.

35. Ferris H, O'Flynn D. Assessment in medical education: what are we trying to achieve? Int J of Higher Edu. 2015;4:139-44. https://doi.org/10.5430/ijhe.v4n2p139.

36. Kogan JR, Hatala R, Hauer KE, Holmboe E. Guidelines: The do's, don'ts and don't knows of direct observation of clinical skills in medical education. Perspect Med Educ. 2017;6:286305. https://doi.org/10.1007/s40037-017-0376-7.

37. Stephenson CR, Rea JR, Bonnes SL, Leasure EL. Telehealth visits as direct observation opportunities. Med Educ. 2020;54:1062-3. https://doi.org/10.1111/medu.14349.

38. Anderson RJ, Cyran E, Schilling L, et al. Outpatient case presentations in the conference room versus examination room: results from two randomized controlled trials. Am J Med. 2002;113:657-62. https://doi.org/10.1016/s0002-9343(02)01320-7.

39. Peters M, Ten Cate O. Bedside teaching in medical education: a literature review. Perspect Med Educ. 2014;3(2):76-88. https:// doi.org/10.1007/s40037-013-0083-y.

40. Petersen K, Rosenbaum ME, Kreiter CD, Thomas A, Vogelgesang SA, Lawry GV. A randomized controlled study comparing educational outcomes of examination room versus conference room staffing. Teach Learn Med. 2008;20:218-24. https://doi.org/10. 1080/10401330802199484.

41. Neher JO, Gordon KC, Meyer B, Stevens N. A five-step "microskills" model of clinical teaching. J Am Board Fam Pract. 1992;5:419-24.

42. Pinnock R, Young L, Spence F, Henning M, Hazell W. Can think aloud be used to teach and assess clinical reasoning in graduate medical education? J Grad Med Educ. 2015;7:334-7. https://doi. org/10.4300/JGME-D-14-00601.1.

43. Sandars J. The use of reflection in medical education: AMEE Guide No. 44. Med Teach. 2009;31:685-95. https://doi.org/10. 1080/01421590903050374.

44. Smith CS, Irby DM. The roles of experience and reflection in ambulatory care education. Acad Med. 1997;72:32-5.

45. Wolpaw TM, Wolpaw DR, Papp KK. SNAPPS: a learner-centered model for outpatient education. Acad Med. 2003;78:893-8. https:// doi.org/10.1097/00001888-200309000-00010.

46. van Galen LS, Wang CJ, Nanayakkara PWB, Paranjape K, Kramer MHH, Car J. Telehealth requires expansion of physicians' communication competencies training. Med Teach. 2019;41:7145. https://doi.org/10.1080/0142159X.2018.1481284.

47. Krupinski EA, Bernard J. Standards and guidelines in telemedicine and telehealth. Healthcare (Basel). 2014;2:74-93. Published 2014 Feb 12. https://doi.org/10.3390/healthcare2010074.

Publisher's Note Springer Nature remains neutral with regard to jurisdictional claims in published maps and institutional affiliations. 